\title{
Lesões no complexo maxilofacial em vítimas de violência no ambiente escolar
}

\author{
M axillofacial injuries in victims of violence at school environment
}

${ }^{1}$ Programa de PósGraduação em Saúde Pública, Departamento de Odontologia, Universidade Estadual da Paraíba.

Avenida das Baraúnas 351, Campus Universitário, Bodocongó. 58109-753 Campina Grande PB. dralessandro@ibest.com.br.
Abstract This study investigated the presence of injuries in the maxillofacial complex in children and adolescents victims of physical violence in school environment. Forty-two proofs involved children and adolescents victims of physical violence in school in the years of 2003 and 2006 were analyzed. The data had been registered in specific form collecting the following variables: gender, age, perpetrator agent, localization of the injuries in the distinct regions of the body, type and number of injuries, existence of injuries in oral cavity and tissue involvement. It was observed that $61.9 \%$ of thevictimsweremale $(61.9 \%)$, age group 13 to 17 years the most reached. In most of the cases $(92.9 \%)$, the perpetrators were friends from school while teachers represented $7.1 \%$ of the cases. Injuries around the head and face were present in $69.1 \%$ of the sample, with $23.8 \%$ of the victims pre senting injuries in the buccal cavity, all of the injuries were situated in soft tissues, mainly in thelips. It was evidenced to be high the existence of injuries in the buccal cavity of the victims of aggression in the school environment, confirming the importance of dentistry in the diagnosis of injuries around the head and face of the victims of physical abuse.

Key words Violence, Multiple trauma, Child abuse
Resumo Este estudo investigou a presença de lesões no complexo maxilofacial em crianças eadolescentes vítimas de violência física no ambiente escolar. Foram analisados 42 laudos deexames de corpo de delito envolvendo crianças e adolescentes vítimas de violência física na escola, nos anos de 2003 e 2006. Os dados foram registrados em formulário específico e as variáveis coletadas foram gênero, idade, agente agressor, localização das lesões nas distintas regiões do corpo, tipo enúmero de lesões presentes, acometimento da cavidade bucal e tipo de envolvimento te cidual. 0 bservou-se que $61,9 \%$ das vítimas eram do gênero masculino, sendo a faixa etária de 13 a 17 anos a mais atingida. Os colegas foram os perpetradoresmaisfrequentes $(92,9 \%$ ) enquanto os professoresforam os agressores em 7,1\% dos casos. Lesões nas regiões da cabeça eface estavam presentes em $69,1 \%$ da amostra, com $23,8 \%$ das vítimas apresentando injúrias na cavidade bucal, sendo que a totalidade das lesões localizadas em tecido mole, princi palmente nos lábios. Constatou-se ser elevada a existência de injúrias na cavidadebucal em vítimas deagressão no ambiente escolar, confirmando a importância da odontologia no diagnóstico de lesões nas regiões da cabeça e face em vítimas de violência física.

Palavras-chave Violência, Traumatismo múltiplo, M aus-tratos infantis 


\section{Introdução}

O Estado continua a ser o principal responsável pela segurança. No entanto, a partir do momento em que os problemas de segurança aumentam em complexidade, novos atores passam a desempenhar um papel nesse domínio. Assim, outros setores da sociedade emergem como determinantes do estado de segurança. Entreeles, destacam-sea saúde e a educação ${ }^{1}$.

No momento atual, a violência é um fenômeno que se observa com frequência crescente em todos os domínios da vida social. Esse fenômeno também ocorre na escola, onde professores e alunos vivenciam no seu cotidiano diferentes formas de violência ${ }^{2-4}$.

No entender de Marriel et al. ${ }^{5}$, a escola é um lugar privilegiado para refletir sobre as questões que envolvem crianças ejovens, pais e filhos, educadores e educandos, bem como as relações que se dão na sociedade. É também nesse universo onde a socialização, a promoção da cidadania, a formação deatitudes, opiniões e o desenvolvimento pessoal podem ser incrementados ou prejudicados.

Quando se aborda a violência contra crianças e adolescentes e a vinculamos aos ambientes onde ela ocorre, a escola surge como um espaço ainda pouco explorado, principalmente com relação ao comportamento agressivo existente entre os próprios estudantes 6 .

Paralelamente a esta preocupação social, verificou-se um grande aumento da investigação sobre este tema, em particular sobre um tipo especial de violência escolar - o bullying - termo de origem inglesa quetem sido utilizado para designar determinadas condutas de agressão/vitimização que ocorrem entre pares, em que 0 abuso de alguém mais forte para com alguém mais fraco, ou o abuso de um grupo sobre uma vítima indefesa, parece ser a característica mais saliente ${ }^{2,3,78}$. Trata-se de comportamentos agressivos que ocorrem nas escolas e que são tradicionalmenteadmitidos como naturais, sendo habitualmente ignorados ou não valorizados, tanto por professores quanto pelos pais ${ }^{6}$.

0 envolvimento no bullying (quer como vítima, quer como agressor) parece afetar entre $15 \%^{7}$ a $66 \%^{8}$ do total dos alunos que frequentam os vários estabelecimentos de ensino. Estes dados têm sido repetidamente obtidos através de diferentes metodologias e instrumentos ${ }^{7}$.

As crianças e os adolescentes se apresentam como um foco de preocupação para pais e educadores, justamente por viver numa sociedade em transformação, tomada por valores instáveis e de curta duração. A agressividade, que faz parte da natureza afetiva do ser humano, quando reprimi$\mathrm{da}$, pode se manifestar como violência. A dificuldade em se perceber a diferença entre ações agressivas e violentas pode promover a repressão dos alunos, os quais por acúmulo desta comportamse ainda mais agressivos, criando-se um ciclo do qual participam alunos e professores 9 .

$U m$ ato é caracterizado como violento quando atende, de acordo com Ferreira e Schramm ${ }^{10}$, às seguintes condições: causar dano a terceiros, usar força física ou psíquica, ser intencional eir contra a vontade de quem é atingido. A violência pode ser considerada sob diversas óticas, sendo, principalmente, classificada em social ou urbana, psicológica e física. Lopes $N$ eto ${ }^{6}$ e $M$ artins ${ }^{7}$ ressaltaram que o bullying ou os maus-tratos entre companheiros manifestam-se de diversas formas: direto e físico, inclui bater ou ameaçar fazêlo, dar pontapés; direto e verbal, que engloba insultar, colocar apelidos ou ofensas verbais; indireto, que se refere a situações como excluir alguém sistematicamente do grupo de pares, ameaçar com frequência a perda da amizade ou a exclusão do grupo como forma de obter algo do outro ou como retaliação de uma suposta ofensa prévia, dentre outros.

A criança eo adolescente são mais suscetíveis a situações violentas com as quais convivem em seu meio, quer seja ele social, familiar ou escolar.

É cediço que, depois do ambiente familiar, a escola é o local que 0 aluno está presente na maior parte de sua vida, sendo caracterizada como o local de aprendizagens, estabelecendo ordens e normas para que os alunos aprendam ${ }^{11}$. Sebastião et al. ${ }^{12}$, ao se reportarem à violência escolar em Portugal, enfatizaram três importantes aspectos: primeiro, a violência aumenta, em particular, nas escolas situadas junto de zonas da periferia degradada, marginal ou de bairros sociais; segundo, a violência preexiste à escola, sendo exterior à mesma, existindo uma inevitabilidade na reprodução da violência contextual em violência escolar e, terceiro, são os alunos de insucesso escolar os mais violentose, em particular, os provenientes de minorias étnicas.

$M$ aldonado ${ }^{13}$ afirma que as crianças em idade escolar podem reproduzir comportamentos que fazem parte de seu cotidiano, tendo a violência doméstica como um dos modelos de relacionamentos presentes em seu dia a dia. Desse modo, pode-se supor que crianças escolares agressivas apresentam tal quadro em decorrência do modelo mantido em seu lar.

Corroborando a afirmativa de Seixas ${ }^{8}$, o crescente interesse pelo estudo no âmbito da violência escolar advém, entre outros fatores, da maior frequência evisibilidadequeas suas manifestações têm 
tido, bem como da consequente preocupação evidenciada pelos diversos profissionais e/ou intervenientes no contexto educativo. Professores, alunos, encarregados de educação, psicólogos são alguns dos diferentes agentes que, de um modo mais direto ou mais indireto, contatam com essa realidade.

No que se refere à existência de lesões maxilofaciais, as regiões da cabeça e face são as áreas mais comumente atingi das em vítimas de violência física, correspondendo a 60,9\%, sendo as abrasões e equimoses as lesões mais frequentes. Injúrias intraorais foram verificadas em $18,9 \%$ das vítimas com lesões na cabeça e face, com os tecidos moles (lábio superior, inferior e mucosa bucal) os mais lesionados $(91,8 \%)^{14}$.

Portanto, com base no exposto, o objetivo deste trabalho foi investigar a presença de lesões no complexo maxilofacial em crianças e adolescentes vítimas de violência física no ambiente escolar.

\section{Metodologia}

Realizou-se um estudo observacional e retrospectivo, com abordagem indutiva e técnica de observação indireta por meio da análise de dados secundários.

A pesquisa foi desenvolvida no município de Campina Grande (PB), localizada no agreste paraibano, na parte oriental do Planalto da Borborema, Região N ordeste do Brasil. A cidade possui uma população de 379.871 habitantes e um Índice de Desenvolvimento Humano (IDH) de 0,721.

Diante deuma situação queenvolveviolência, 0 artigo 158 do Código de Processo Penal estabelece que "Quando a infração deixar vestígios, será indispensável o exame de corpo de delito, direto ou indireto, não podendo supri-lo a confissão do acusado"15. Deste modo, vítimas de violência são encaminhadas ao Departamento de M edicina Legal para a realização do referido exame, visando à quantificação e qualificação das lesões corporais existentes. Portanto, embasado na legislação brasileira, definiu-secomo local de coleta dos dados a Unidade de M edicina Legal de Campina Grande (PB).

$O$ universo pesquisado compreendeu a análise de 11.624 laudos médicos de exames de corpo de delito realizados no período compreendido entre janeiro de 2003 a dezembro de 2006. Objetivando atribuir maior fidelidade aos registros, bem como recuperar informações que porventura não estivessem descritas nos laudos, foram também analisados os boletins de ocorrência (BO), totalizando 23.248 documentos examinados. Adotou-se como critério de inclusão no estudo a presença de lesões corporais provenientes de agressão física. Desse modo, constatou-se que, do total de laudos, 1.070 se referiam a casos de violência física envolvendo crianças e adolescentes de zero a dezessete anos de idade. A amostra estudada foi composta por 42 laudos (3,9\%) referentes a casos confirmados de agressões físicas contra crianças e adolescentes no ambiente escolar, objeto de estudo do presente trabalho.

0 instrumento de pesquisa consistiu de um formulário específico, sendo os dados coletados por um único examinador. A violência escolar foi estudada nas seguintes formas: a) entre alunos; $b$ ) de professor para aluno; c) de funcionário para aluno e d) de agentes externos para 0 aluno. Foram verificadas também variáveis como gênero, idade, localização das lesões nas distintas regiões do corpo, tipo e número de lesões presentes, acometimento da cavidade bucal e tipo de envolvimento tecidual.

\section{Análise estatística}

0 programa utilizado para a realização das análises estatísticas foi o Epi Info 3.4. Para a análise dos dados, foram obtidas as frequências absolutas epercentuais (técnicas de estatística descritiva). A associação significativa entre as variáveis foi verificada por meio de análise bivariada (teste exato de Fisher), considerando o valor para rejeição da hipótesenula de $p<0,05$.

Este estudo foi registrado no SISNEP (CAAE0023.0.133.000-05) eaprovado pelo ComitêdeÉtica em Pesquisa da Universidade Estadual da Paraíba.

\section{Resultados}

A distribuição dos laudos segundo 0 ano revelou que a maioria das ocorrências foi registrada no ano de 2005 (37,5\%), seguido dos anos de 2003 e 2004 , com $23,8 \%$ cada um, e de $16,7 \%$ para 0 ano de 2006. A análise das vítimas quanto ao gênero mostra que $61,9 \%$ eram meninos e $38,1 \%$ eram meninas, correspondendo a uma proporção de 1,6:1. Quanto à faixa etária, 2,4\% tinham entrezero e quatro anos, $7,1 \%$, entre cinco e oito anos, $9,5 \%$, entrenovee dozeanos e $81,0 \%$, entretreze edezessete. A média deidade foi de catorze anos $( \pm 3,23)$.

No tocante ao horário, $45,7 \%$ das ocorrências foram no turno da manhã, 40,0\%, à tardee $14,3 \%$, à noite. A Tabela 1 apresenta a distribuição das vítimas quanto ao gênero segundo o horário da agressão.

Quanto ao agressor, a análise dos laudos mostrou que em $7,1 \%$ dos casos o agressor se consti- 
tuiu em um professor, enquanto que $92,9 \%$ dos perpetradores foram colegas da vítima.

Registrou-se um total de 61 lesões, com média de 1,45 lesão por vítima. A distribuição segundo 0 número de lesões presentes revel ou que $66,7 \%$ das vítimas possuíam um único tipo de lesão (por exemplo, contusão), 21,4\% apresentavam dois diferentes tipos de lesões (por exemplo, contusão e edema) e 11,9\% tinham três diferentes tipos delesões (por exemplo, contusão, edema e escoriação). Ao se dicotomizar o número de lesões (um tipo e dois ou mais tipos), não se observou associação com o gênero $(p>0,05)$. Os diversos tipos de lesão encontrados são apresentados na Tabela 2.

No que se refereà área do corpo atingida, lesões na região da cabeça eface (CB-FC) exclusivamente estavam presentes em $50,0 \%(n=21)$ dos laudos, conforme pode ser visto na Tabela 3. Porém, quando se verifica a existência de lesão nessa região asso- ciada à outra área, esse percentual atinge $69,1 \%$.

$\mathrm{Na}$ Tabela 4, é possível verificar a relação entre o perpetrador e a região do corpo lesionada. Observa-se que em $92,9 \%$ das situações 0 agressor se constitui em um colega da vítima. No entanto, foram registrados casos de violência tendo como perpetrador o professor.

Ao se analisar a presença de lesões na cavidade bucal, observou-se que $23,8 \%$ da amostra possuíam injúrias nessa região. $A$ análise bivariada entre a presença de lesão na cavidade bucal e o gênero não se mostrou estatisticamente significante, conforme pode ser visto na Tabela 5.

Dos dez casos de envolvimento da cavidade bucal, 50,0\% envolviam a maxila, 30,0\%, a mandíbulae $20,0 \%$, ambas as regiões. 0 tipo de envolvimento tecidual existente revela que $100,0 \%$ das agressões atingiram exclusivamentetecido mole, predominando injúrias noslábios $(80,0 \%)$ ena mucosa $(20,0 \%)$.

Tabela 1. Distribuição das vítimas segundo o gênero e de acordo com o horário de ocorrência da agressão.

\begin{tabular}{|c|c|c|c|c|c|c|c|c|}
\hline \multirow{3}{*}{ Gênero } & \multicolumn{6}{|c|}{ Horário } & & \\
\hline & \multicolumn{2}{|c|}{ M anhã } & \multicolumn{2}{|c|}{ Tarde } & \multicolumn{2}{|c|}{ Noite } & \multicolumn{2}{|c|}{ Total $^{*}$} \\
\hline & $n$ & $\%$ & $n$ & $\%$ & $\mathrm{n}$ & $\%$ & $\mathrm{n}$ & $\%$ \\
\hline Feminino & 3 & 23,1 & 8 & 61,5 & 2 & 15,4 & 13 & 37,1 \\
\hline M asculino & 13 & 59,1 & 6 & 27,3 & 3 & 13,6 & 22 & 62,9 \\
\hline TOTAL ${ }^{*}$ & 16 & 45,7 & 14 & 40,0 & 5 & 14,3 & 35 & 100,0 \\
\hline
\end{tabular}

*Em 7 laudos, não há registro do horário de ocorrência.

Tabela 2. Distribuição dos tipos de lesões existentes nas vítimas de violência.

\begin{tabular}{lrr}
\hline \multirow{2}{*}{ Tipo de lesão presente } & \multicolumn{2}{c}{ Frequência } \\
\cline { 2 - 3 } & \multicolumn{1}{c}{$\mathrm{n}$} & \multicolumn{1}{c}{$\%$} \\
\hline Contusão/edema & 1 & $2,4 \%$ \\
Edema & 1 & $2,4 \%$ \\
Equimose & 4 & $9,5 \%$ \\
Equimose/edema & 4 & $9,5 \%$ \\
Equimose/edema/outra & 1 & $2,4 \%$ \\
Escoriação & 18 & $42,9 \%$ \\
Escoriação/edema & 1 & $2,4 \%$ \\
Escoriação/equimose & 2 & $4,8 \%$ \\
Escoriação/equimose/edema & 3 & $7,1 \%$ \\
Escoriação/fratura & 1 & $2,4 \%$ \\
Escoriação/fratura/edema & 1 & $2,4 \%$ \\
Ferimento & 2 & $4,8 \%$ \\
Fratura & 1 & $2,4 \%$ \\
Outra & 2 & $4,8 \%$ \\
Total & 42 & $100,0 \%$ \\
\hline
\end{tabular}

Tabela 3. Distribuição das lesões segundo a região do corpo atingida.

\begin{tabular}{lrr}
\hline \multirow{2}{*}{ Local do corpo atingido } & \multicolumn{2}{c}{ Frequência } \\
\cline { 2 - 3 } & \multicolumn{1}{c}{$\mathrm{n}$} & \multicolumn{1}{c}{$\%$} \\
\hline Cabeça-face & 21 & $50,0 \%$ \\
Cabeça-face/tronco - membros & 7 & $16,7 \%$ \\
$\begin{array}{l}\text { superiores } \\
\text { Cabeça-face/tronco - membros }\end{array}$ & 1 & $2,4 \%$ \\
superiores/inferiores & & \\
Membros inferiores & 2 & $4,8 \%$ \\
Tronco-membros superiores & 9 & $21,4 \%$ \\
Tronco-membros superiores/ & 2 & $4,8 \%$ \\
inferiores & & \\
Total & 42 & $100,0 \%$ \\
\hline
\end{tabular}


Tabela 4. Distribuição das lesões nas diferentes regiões do corpo, segundo o perpetrador.

\begin{tabular}{|c|c|c|c|c|c|c|c|c|c|c|c|c|c|c|}
\hline \multirow{3}{*}{ Agressor } & \multicolumn{12}{|c|}{ Região do corpo atingida } & & \\
\hline & \multicolumn{2}{|c|}{ CB-FC } & \multicolumn{2}{|c|}{ CB-FC/Tr-MS } & \multicolumn{2}{|c|}{ CB-FC/Tr-M S/M I } & \multicolumn{2}{|c|}{ Tronco-M S } & \multicolumn{2}{|c|}{ Tr-M S/ M I } & \multirow{2}{*}{\multicolumn{2}{|c|}{$\frac{M I}{\%}$}} & \multicolumn{2}{|c|}{ Total $^{*}$} \\
\hline & $\mathrm{n}$ & $\%$ & $\mathrm{n}$ & $\%$ & $\mathrm{n}$ & $\%$ & $\mathrm{n}$ & $\%$ & & ר & & & $\mathrm{n}$ & $\%$ \\
\hline Professor & 2 & 66,7 & - & - & - & - & 1 & 33,3 & - & & - & - & 3 & 7,1 \\
\hline Colega & 19 & 48,7 & 7 & 17,9 & 1 & 2,6 & 8 & 20,6 & 2 & 5,1 & 2 & 5,1 & 39 & 92,9 \\
\hline Total & 21 & 50,0 & 7 & 16,6 & 1 & 2,4 & 9 & 21,4 & 2 & 4,8 & 2 & 4,8 & 42 & 100,0 \\
\hline
\end{tabular}

CB-FC - Cabeça-face; Tr-M S - Tronco-membros superiores; MI - M embrosinferiores.

Tabela 5. Distribuição das vítimas segundo a presença de lesão na cavidade bucal, de acordo com o gênero.

\begin{tabular}{lrrrrrr}
\hline \multirow{2}{*}{ Presença de lesão na cavidade bucal } & \multicolumn{2}{c}{ Gênero } & \multirow{2}{*}{ Total } & Valor de $\mathrm{p}$ & OR & (IC95\%) \\
\cline { 2 - 3 } & Feminino & Masculino & & & \\
\hline Não & 14 & 18 & 32 & & 1 \\
Sim & 2 & 8 & 10 & P =0,164 & 3,11 \\
Total & 16 & 26 & 42 & & $(0,56-17,02)$ \\
\hline
\end{tabular}

\section{Discussão}

A violência acometeo mundo contemporâneo em todas as suas instâncias e se manifesta de variadas formas. Ela está presente em toda sociedade e não se restringe a determinados espaços, a determinadas classes sociais, a determinadas faixas etárias ou a determinadas épocas. É equivocado pensar que ela se vincula apenas e diretamente à pobreza, aos grandes centros urbanos, aos adultos e aos dias dehoje. Verifica-se, por exemplo, o crescimento das práticas da violência entre os jovens de classes médias e de segmentos privilegiados da sociedade, nos seus diferentes espaços de atuação: na família, na escola ou na rua ${ }^{16}$.

A existência deum conjunto de situações queé designado globalmente por violência na escola tem dado origem, nos anos mais recentes, a diversos debates públicos e a numerosas referências nos meios de comunicação social. Um primeiro passo para a clarificação do conceito de violência diz respeito à compreen são da multidimensionalidade do fenômeno. Agressão/perseguição psicológica, agressão física, assalto/roubo, indisciplina grave são manifestações do fenômeno que o conceito de violência procura descrever ${ }^{8,12}$. A escola deve ser um local de bem-estar e de aprendizagem.

0 tema da violência escolar tem sido objeto de uma preocupação crescente nas últimas duas dé- cadas, quer por parte da sociedade em geral, quer por parte da comunidade educativa, em particular. Paralelamente a esta preocupação social, verificou-se um expressivo aumento da investigação sobre este tema, em particular sobre um tipo especial de violência escolar - o bullying - o qual pode ser utilizado para conceituar a agressão sistemática eintencional entre pares ${ }^{12}$.

De acordo com Gonçalves et al. ${ }^{4}$, existe grande perplexidade da parte do professor que, muitas vezes, fica sem saber como agir para resolver e prevenir os múltiplos conflitos que surgem no cotidiano escolar. O que se observa é que, na maioria das vezes, ele tem muitas dificuldades de lidar com as situações de conflito, deforma a propiciar ao aluno experiências educativas deinteração social construtiva que favoreçam a sua formação ética e minimizem a violência na escola. Em contrapartida, pensa-se que a escola é o espaço por excelência em que o indivíduo tem possibilidades devivenciar demodo intencional e sistemático formas construtivas de interação, adquirindo um saber que propicie as condições para o exercício da cidadania.

A área da saúde tem, tradicionalmente, concentrado seus esforços em atender os efeitos da violência: a reparação dos traumas e lesões físicas nos serviços de emergência, na atenção especial izada, nos processos de reabilitação, nos aspectos médico-legais enos registros de informações. Ulti- 
mamente, sobretudo em relação a alguns agravos, como violência contra a criança e a mulher, começa a haver uma abordagem que inclui aspectos psicossociais e psicológicos, tanto em relação ao impacto sobre as vítimas como em relação à caracterização do agressor ${ }^{17}$.

0 objeto da presente pesquisa foi estudar as lesões maxilofaciais existentes em crianças e adolescentes vítimas de violência no ambiente escolar. $N$ esse sentido, é relevante destacar o ineditismo do estudo, visto que não foram encontrados trabaIhos semelhantes na literatura nacional e internacional que tenham procurado estudar essa relação, o que dificultou sobremaneira a comparação dos resultados obtidos. Outro importante aspecto refere-se à amostra analisada, a qual foi composta por laudos médicos de exames de corpo de delito de vítimas de agressão no ambiente escolar, existindo uma minuciosa descrição da quantificação e qualificação das lesões presentes.

Este estudo revelou uma maior predominância de vítimas do gênero masculino, concordando com o estudo de $\mathrm{M}$ artins ${ }^{7}$. Entretanto, Lopes $\mathrm{N}$ eto ${ }^{6}$ e Seixas ${ }^{8}$ relataram que as diferenças relativas ao gênero não são muito evidentes no seio de cada grupo, existindo uma ligeira superioridade no gê nero masculino no caso dos alunos agressores e vítimas-agressivas, e no gênero feminino, no caso dos alunos vítimas.

A análise da idade mostra que $81,0 \%$ das vítimas tinham acima de treze anos de idade. Tais dados discordam de Carvalhosa et al. ${ }^{2}$, os quais relataram que os alunos mais novos são mais frequentemente vitimados do que os alunos mais velhos. É lícito salientar a peculiaridade do presente estudo, o qual analisou dados secundários. É cediço que muitas das situações de violência não são reportadas, principalmente quando envolvem crianças pequenas.

N este estudo, os próprios colegas de escola foram os perpetradores mais frequentes $(92,9 \%)$ demonstrando o comportamento agressivo existente entre os próprios estudantes ${ }^{6}$. Contudo, re gistros de agressão por parte de professores também foram encontrados.

É um achado comum que, quando um indivíduo é agredido por qualquer razão, às áreas da cabeça e face, frequentemente, estão envolvidas. Portanto, não se constitui uma surpresa o fato de que em crianças abusadas fisicamente essas regiões sejam atingidas ${ }^{14,18}$. Os danos que acometem 0 sistema estomatognático devem ser avaliados pelo cirurgião-dentista, quetem competência legal para realizar perícias, entre elas as de lesões em vítimas que sofreram danos corporais e/ou funcionais na região correspondente à sua área de atuação ${ }^{19}$.
A análise das lesões segundo a região do corpo atingida revela que em $69,1 \%$ dos laudos existiam registro de lesões na região da cabeça e face, val ores estes superiores aos 60,9\% encontrados por Cavalcanti ${ }^{14} \mathrm{em}$ crianças e adolescentes vítimas de agressão física em estudo realizado no município deJ oão Pessoa, Paraíba. Esses números corroboram a assertiva de que estas áreas se constituem no principal local a ser lesionado quando da violência física.

A cavidade bucal, por sua vez, foi injuriada em $23,8 \%$ dos casos, existindo uma distribuição similar entre os maxilares superior e inferior, e havendo um predomínio de injúrias aos tecidos moles. Cavalcanti ${ }^{14}$ reportou $18,9 \%$ de lesões na cavidade bucal, sendo os tecidos moles os mais atingidos, confirmando os achados desta pesquisa.

$N$ a verdade, o essencial das ocorrências violentas na escola não consi ste em ações de grande violência cometidas por grupos de jovens marginais, mas traduz-se em situações de pequena violência cotidiana entre alunos (agressões, intimidação, perseguição e ameaça), geralmente de alunos mais velhos sobre os mais novos, dos mais fortes sobre os mais fracos. Deste modo, os "empurrões", os "pontapés" e "tapas" e pode ser considerados habituais ${ }^{12}$. M artins ${ }^{7}$ acrescenta ainda que a criança vitimada pode estar em desvantagem numérica, ou só entre muitos, ser menos forte, ou simplesmente ser menos autoconfiante.

A adolescência éuma etapa do desenvolvimento humano em que as patologias não são tão frequentes, ou seja, espera-se que a morbidade neste grupo não seja elevada²0.

Além da violênciafísica, crianças eadolescentes pobres estão, frequentemente, sujeitos também à violência psicológica que se manifesta nos processos de avaliação e nas formas de interação que se estabelecem entre diretores, professores, funcionários, alunos e responsáveis ${ }^{21}$.

Dada a longa experiência da saúde pública na intervenção comunitária, este é um âmbito onde ela pode lograr êxito, caso se articule ao serviço social edeorientação familiar, em sua atuação de prevenção em todos os níveis. Os dados que se tem hoje, no país, sobre estetipo deviolência, são escassos e pobres, por se tratar de um problema em que a prevenção tem que atuar, em primeiro lugar, na sensibilização e no avanço da consciência social ${ }^{16}$.

O comportamento agressivo é um dos problemas associados à exposição das crianças à violência doméstica, fazendo parte dos sintomas de distúrbios emocionais e dos problemas de comportamento causados por este tipo de violência ${ }^{13}$.

A despeito da extensiva busca realizada na literatura, não se obteve sucesso em localizar estudos 
semelhantes que tenham procurado relacionar a existência de lesões no complexo maxilofacial ea violência no ambiente escolar.

Este estudo realizado com laudos médicos de exames de corpo de delito revela dois importantes aspectos: o primeiro expõe um novo campo de estudos para pesquisadores das áreas de educação e das ciências da saúde; o segundo, confirma a importância da odontologia no diagnóstico de lesões nas regiões da cabeça e face em vítimas de violência física. A estes fatos, soma-se a necessidade da realização de estudos adicionais, epidemiológicos ou não, que visem determinar não somente os perfis da vítima e do perpetrador, mas também identificar e descrever as inúmeras lesões que podem acometer os maxilares.

\section{Conclusão}

Apesar da pequena amostra analisada, a existência de injúrias na cavidade bucal em vítimas de agressão no ambiente escolar mostrou-se elevada, demonstrando ser importante a realização de investigações futuras, que busquem estudar a presença ea distribuição de lesões no complexo maxilofacial.

\section{Agradecimentos}

0 autor agradece o auxílio financeiro recebido do Conselho Nacional de Desenvolvimento Científico e Tecnológico, Processo 50.4357/2004-2. Agradecimentos são dirigidos também ao Dr. Jaime Rodrigues de Melo Filho, Diretor da Unidade de M edicina Legal de Campina Grande (PB). 


\section{Referências}

1. Liberal EF, Aires RT, Aires MT, Osório ACA. Escola segura. J Pediatria 2005; 81:s155-s163.

2. Carvalhosa SF, Lima L, Matos M G. Bullying - A provocação/vitimação entre pares no contexto escolar português. Aná Psicológica 2001; 19:523-537.

3. Blank D, Liberal EF. O pediatra e as causas externas de morbimortalidade. J Pediatria 2005; 81:s119-s122.

4. Gonçalves MAS, Piovesan OM, Link A, Prestes LF, Lisboa JG. Violência na escola, práticas educativas e formação do professor. Cad Pesqui 2005; 35:635-658.

5. Marriel LC, Assis SG, Avanci JQ, Oliveira RVC. Violência escolar e auto-estima de adolescentes. Cad Pesqui 2006; 36:35-50.

6. Lopes Neto AA. Bullying: comportamento agressivo entre estudantes. J Pediatria 2005; 81:s164-s172.

7. Martins MJD. Agressão e vitimação entre adolescentes, em contexto escolar: Um estudo empírico. Aná Psicológica 2005; 23:401-425.

8. Seixas SR. Violência escolar: M etodologias de identificação dos alunos agressores e/ou vítimas. Aná Psicológica 2005; 23:97-110.

9. Anser $\mathrm{MACl}$, Joly MCRA, Vendramini CM M . Avaliação do conceito de violência no ambiente escolar: visão do professor. Psicologia 2003; 5:67-81.

10. Ferreira AL, Schramm FR. Implicações éticas da violência doméstica contra a criança para profissionais de saúde. Rev. Saude Publica 2000; 34:659-665.

11. Silva M P, Carvalho $\mathrm{CH}$. violência e ética docente no espaço escolar (Patrocínio, M G, 2001-2002). Rev CESUC 2002; 4:1-8.

12. Sebastião J, Alves M G, Campos J. Violência na escola: Das políticas aos quotidianos. Sociologia 2003; 41:37-62.

13. M aldonado DPA. 0 comportamento agressivo de crianças do sexo masculino na escola e sua relação com violência doméstica [dissertação]. São Carlos (SP): Universidade Federal de São Carlos; 2003.
14. Cavalcanti AL. Prevalência, características e manifestações bucais de maus-tratos físicos em crianças e adolescentes na região metropolitana de João Pessoa-PB [tese]. João Pessoa (PB): Programa Integrado de Pós-Graduação em Odontologia, Centro de Ciências da Saúde da Universidade Federal da Paraíba; 2002.

15. Brasil. Código de Processo Penal. 7ạ ed. São Paulo: Revista dos Tribunais, 2002. 928p.

16. Camacho LMY. As sutilezas das faces da violência nas práticas escolares de adolescentes. Educ Pesq 2001; 27: $123-140$.

17. M inayo MCS. A violência social sob a perspectiva da saúde pública. Cad Saude Publica 1994; 10:7-18.

18. Needleman HL. Orofacial trauma in child abuse: types, prevalence, management, and the dental profession's involvement. Ped Dent 1986; 8:71-80.

19. Frugoli OU. Avaliação dos danos do complexo maxilomandibular provocados por violência interpessoal: análise comparativa entre os pareceres odontológicos e os laudos médicos emitidos pelo Instituto M édico-Legal de São Paulo nos anos de 1993 e 1998 [dissertação]. São Paulo (SP): Faculdade de Odontologia, Universidade de São Paulo; 2000.

20. Meneghel SN, Giugliani EJ, Falceto O. Relações entre violência doméstica e agressividade na adolescência. Cad Saude Publica 1998; 14:327-335.

21. Zaluar $A$, Leal $M C$. Violência extra e intra-muros. Rev Bras Ci Soc 2001; 16:145-164.

Artigo apresentado em 28/05/2008

Aprovado em 11/11/2008 